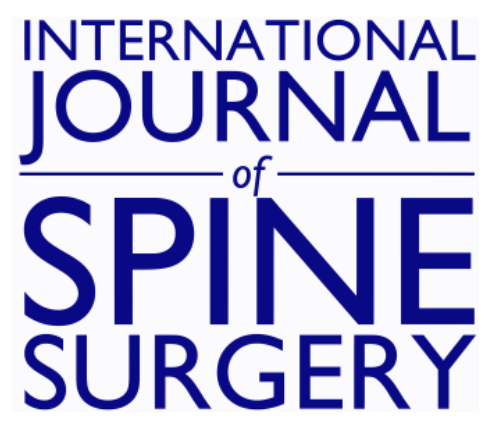

\title{
Possible Correlation Between Kyphosis of Lumbar Osteoporosis Fractures and the Spinal Signal Intensity Ratio (SSIR)
}

Tarek Omar Pacha, Amir Ghasemi, Mohamed Omar, Tilman Graulich, Christian Krettek, Yoon Wai Weng and Timo Stubig

Int J Spine Surg 2021, 15 (3) 478-484

doi: https://doi.org/10.14444/8069

http://ijssurgery.com/content/15/3/478

This information is current as of April 26, 2023.

Email Alerts Receive free email-alerts when new articles cite this article. Sign up at:

http://ijssurgery.com/alerts

The International Journal of Spine Surgery

2397 Waterbury Circle, Suite 1,

Aurora, IL 60504, Phone: +1-630-375-1432 


\title{
Possible Correlation Between Kyphosis of Lumbar Osteoporosis Fractures and the Spinal Signal Intensity Ratio (SSIR)
}

\author{
TAREK OMAR PACHA, MD, ${ }^{1}$ AMIR GHASEMI, MD, ${ }^{2}$ MOHAMED OMAR, MD, ${ }^{1}$ TILMAN GRAULICH, \\ MD,${ }^{1}$ CHRISTIAN KRETTEK, MD ${ }^{1}$ YOON WAI WENG, MD, ${ }^{2}$ TIMO STUBIG, MD ${ }^{1}$ \\ ${ }^{I}$ Trauma Department, Hannover Medical School (MHH), Lower Saxony, Germany, ${ }^{2}$ Center for Spinal studies and Surgery, Nottingham University Hospital, \\ United Kingdom
}

\begin{abstract}
Background: The aim of this study was to examine the correlation between the risk of increasing kyphosis as well as collapse of the osteoporotic vertebral body fractures and the intensity of the bone edema in magnetic resonance imaging (MRI) scans. Inclusion criteria included the following: age $>18$ years and osteoporotic vertebral body fracture grade I-IV according to OF classification. Exclusion criteria included the following: other pathological fractures due to primary tumors or metastasis, OF grade V fractures, and AO type B or C fractures.

Methods: This was a retrospective study from pseudonymized data of a tertiary spine center. No additional imaging were performed. Measurements of bisegmental kyphosis angle of the fracture for involvement of both endplates and monosegmental angle for involvement of 1 endplate, as well as vertebral body height loss in initial radiographs and at follow-ups after 3 and 6 months have been performed. Also, the initial signal intensity of the vertebral body edema was measured using integrated tool of the DICOM viewer (Impax V6.5 Agfa, Brentford, UK) in addition to the signal intensity of the cerebrospinal fluid (CSF) as reference for T1, T2, and separate target illumination radar (STIR) sequences of the MRI scans. A quotient from the signal intensity of the vertebral body edema and the reference (CSF) has been generated. Patients have been divided to 4 groups according to the ratio $(<1,1-2,2-3,>3)$ and compared in regards to the results of the degree of kyphosis and vertebral collapse at follow-ups and final examination. The statistical analysis was performed using linear regression using statistic software SPSS version 26.

Results and Conclusions: Forty-four patients have been included: 9 males and 35 females with an average age of 71.5 years. The analysis showed a significant correlation between the increasing kyphosis at follow-ups and the quotient of the signal intensity for STIR and T2 weighing with $P=.002$ (SD \pm 2.664 ) for STIR and $P=.001$ (SD \pm 1.616 ) for T2 sequences. Furthermore, there was only a correlation between the intensity ratio and kyphosis for STIR weighting at last examination $(P=.017$; $\mathrm{SD} \pm 1.360)$. There was no correlation between the height loss and the signal intensity.
\end{abstract}

Level of Evidence: Level 2

Lumbar Spine

Keywords: spine, osteoporotic fractures, methods, MRI

\section{INTRODUCTION}

Although traumatic vertebral body fractures occurring in different age groups are associated with high energy trauma or fall from significant height, osteoporotic vertebral body fractures usually take place after low energy impact for patients older than 60 years. ${ }^{1-4}$ Within the group of osteoporosisassociated fractures, vertebral body injuries represent the largest portion. ${ }^{5}$ Due to the currently high and increasing incidence, unpredictable outcome as well as demographic changes favoring this type of fractures, osteoporotic fractures remain an important public and clinical health issue. ${ }^{6}$ Furthermore, the rate of osteoporotic vertebral body fractures increases with age. ${ }^{4,7}$ Several factors influence the decision in regard to surgical or conservative therapy. ${ }^{7,8}$ Controversy persists at this point, ${ }^{9}$ but regarding fractures associated with osteoporosis, there is a tendency for authors recommending operative treatment ${ }^{10}$ based on localization, pain level, and fracture classification. Gonschorek et $\mathrm{al}^{8}$ report unstable fractures such as types A4, B, and C to treat fractures surgically. Schnake et $\mathrm{al}^{11}$ recommended a new classification and a point system for decision-making in osteoporotic fracture care based on the initial images. Yang et $\mathrm{al}^{12}$ in 2016 report faster pain relief, better functional results, and fewer 
complications with vertebroplastic treatment of painful osteoporosis fractures.

Moreover, progressive vertebral kyphosis leads to significantly more complications than simple chronic pain. In addition to postural damage, a reduction in lung function and possibly gastrointestinal malfunction may occur in certain cases. ${ }^{13,14}$

At the moment, the stability of a simple impression of 1 or both endplates cannot be predicted, hence multiple plain radiographs are necessary to detect further collapse of osteoporotic vertebral body fractures. ${ }^{15}$

To distinguish fresh from old fractures, regular use of magnetic resonance imaging (MRI) is recommended..$^{8,16-19}$ Furthermore, studies have shown, obtaining preoperative MRI images for old patients requiring surgery can lead to changes to the surgical plan in up to $60 \%$ of the cases due to edema in adjacent vertebral bodies or missing edema in vertebral bodies, which seemed to be fractured in plain x-ray or computed tomography scan. ${ }^{18}$

Corresponding to the signal weighting in the MRI, even in the absence of height loss, bone edema is already evident as an indication of damage to the trabecular structure. ${ }^{19}$

However, a precise index has not been described so far. With the help of the cerebrospinal fluid (CSF) as a reference value, we suggest relating the measured edema signal intensity as a reference. According to the work of Luoma et $\mathrm{al}^{20,21}$ and Smith et al, ${ }^{22}$ the signal intensity of the CSF can be assumed to be constant, largely regardless of its chemical composition.

Therefore, from the authors' point of view, the CSF is well suited as a largely unchangeable reference to determine the quantity of vertebral bone edema. Calculating the spinal signal intensity ratio (SSIR) by dividing the edema intensity in the fractured vertebra, with the intensity of the spinal fluid, the probability of vertebral collapse can be estimated.

Applying this SSIR could help the surgeon to make a statement about its tendency to collapse or angulate further.

If a valid correlation is found here, it facilitates to predict the probability of a secondary collapse reaching a conclusion to advise an operative or nonoperative therapy. On the other hand, radiation exposure for retrospectively unnecessary follow-up could be avoided.

\section{MATERIALS AND METHODS}

A retrospective evaluation based on pseudonymized data was carried out for this study. In the period between 2013 and 2015, every patient with a vertebral body fracture in the thoracic or lumbar spine after trauma, who was treated in a tertiary Spine Center due to existing osteoporosis, was included in the study. The patients were subjected to protocols corresponding to everyday clinical practice. No additional x-ray or MRI examinations were arranged for the study.

At first, the MRI signal intensity for CSF and in the vertebral body with bone edema was measured using a radiology software (Impax V6.5 Agfa, Brentford, UK), so we could calculate the SSIR by dividing the edema intensity in the fractured vertebra, with the intensity of the spinal fluid in T1 and T2 as well as separate target illumination radar (STIR) series. In follow-up examination, the patients were re-evaluated 2 times via $\mathrm{x}$-ray, and the amount of collapse and focal kyphotic angle of the affected vertebral bodies was documented.

The decision for operative or conservative care was made according to the customary and internationally recognized standards.

\section{Inclusion Criteria}

- Age $>18$ years

- Osteoporosis fractures grades 1-4 according to OF classification ${ }^{11}$

- Pathological fractures: osteoporotic fractures

- Fracture of at least 1 vertebral body

- Fractures of thoracic or lumbar vertebral body

\section{Exclusion Criteria}

- Pathological neoplastic fractures

- Osteoporosis fractures(OF) grade 5 according to OF classification ${ }^{11}$

- AO type B and C fractures

Analyzing the MRI, both the signal intensity of the edematous vertebral body as well as the corresponding spinal fluid were documented in T1, T2, and STIR weightings.

In this fashion, we then calculated a decimal number for each vertebral body that was represented as a quotient of the vertebral body edema to the signal intensity of the spinal fluid.

We then divided the patients into 4 groups according to their measured ratio (Table 1). 
Table 1. Distribution of ratio and group.

\begin{tabular}{lc}
\hline Group & Ratio \\
\hline 1 & $<1$ \\
2 & $1-2$ \\
3 & $2-3$ \\
4 & $>3$ \\
\hline
\end{tabular}

\section{Statistical Methods}

Statistical analysis was performed with SPSS V26 (IBM, Armonk, New York) using a commercial personal computer (Windows 7 Professional, Microsoft Corporation, Redmond, WA).

A linear regression analysis was performed $(\alpha=$ $0.05)$ to quantify the quality of the model, determined by $R^{2}$ and the statistical relationship between ratio and instability of the vertebral body.

\section{RESULTS}

\section{Demographic Data}

Overall, the data from 44 patients could be extracted in the period from January 2013 to September 2015. Due to a moderate compliancy, data histories could not be obtained without gaps for all parameters. We examined 9 male and 35 female patients. Of these, 32 were smokers and 7 were nonsmokers. In 5 patients it was unclear. The age span was almost normally distributed between 50 and 90 years old (Figure 1). Follow-up with radiological controls as well as the final examination occurred after 1 to 48 months (mean, 18.18 months) after trauma.

\section{Correlation Analysis}

The graphic correlation for the T2 weighting and for the STIR weighting is plotted in Figures 2 and 3. For both weightings shown, a correlation between the increase in the values for the actual quotient and the kyphotic tendency in the follow-up can be seen.

\section{Linear Regression Analysis}

We found a significant relationship for the ratios in the STIR weighting and the T2 weighting with respect to the change in the kyphosis angle at the time of follow-up with $P=.002$ ( $\mathrm{SD} \pm 2.664)$ for the STIR weighting and $P=0.001(\mathrm{SD} \pm 1.616)$ for the T2 weighting. $R^{2}$ shows at 0.565 that the model might explain the variances at the time of follow-up. At the time of the final examination, the results of the STIR-weighted measurements for the kyphosis angle remain significant $(P=.017 ; \mathrm{SD} \pm 1.360)$. The T2-weighted measurements are not significantly

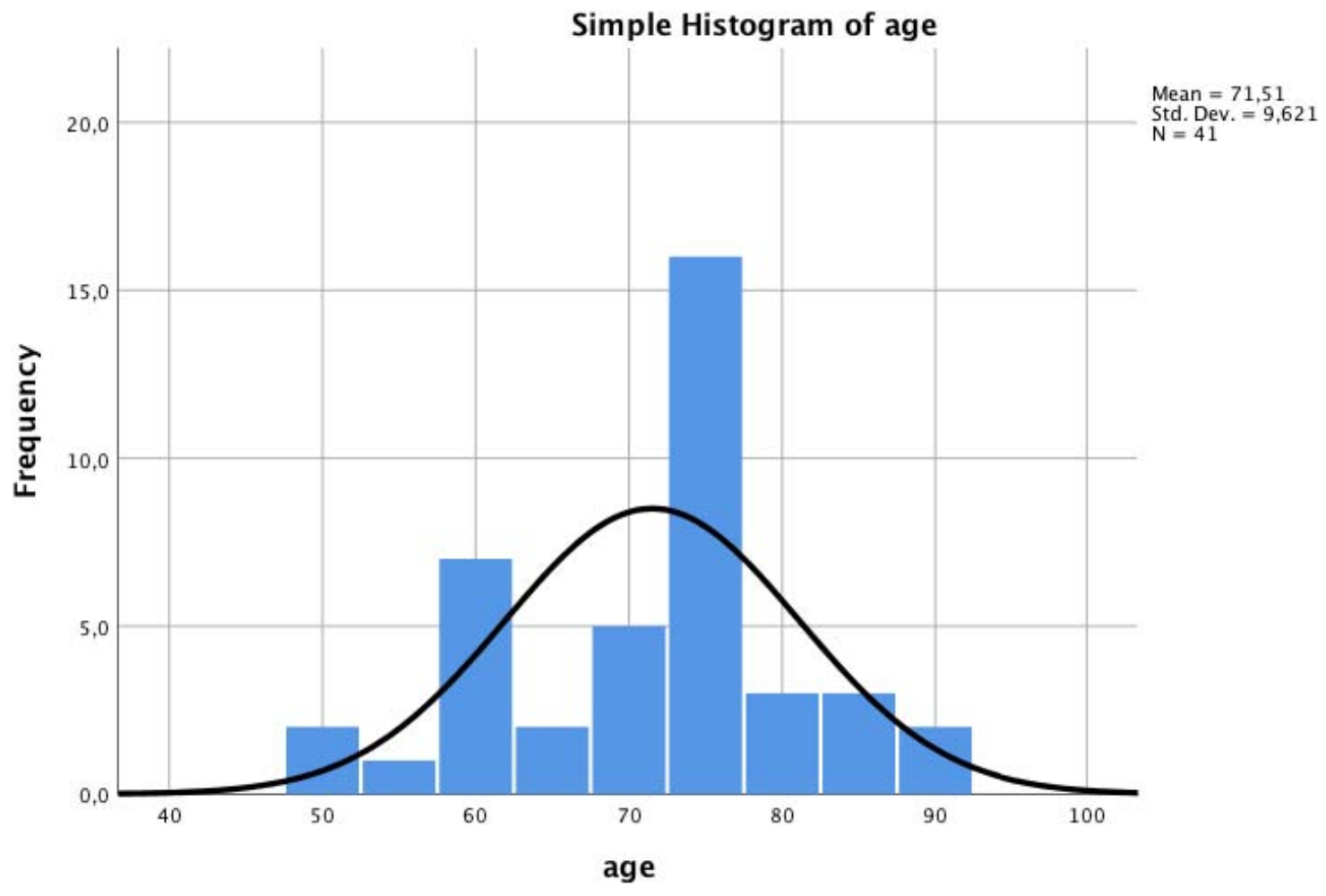

Figure 1. Distribution of age. 


\section{T2: Correlation kyphosis follow-up}

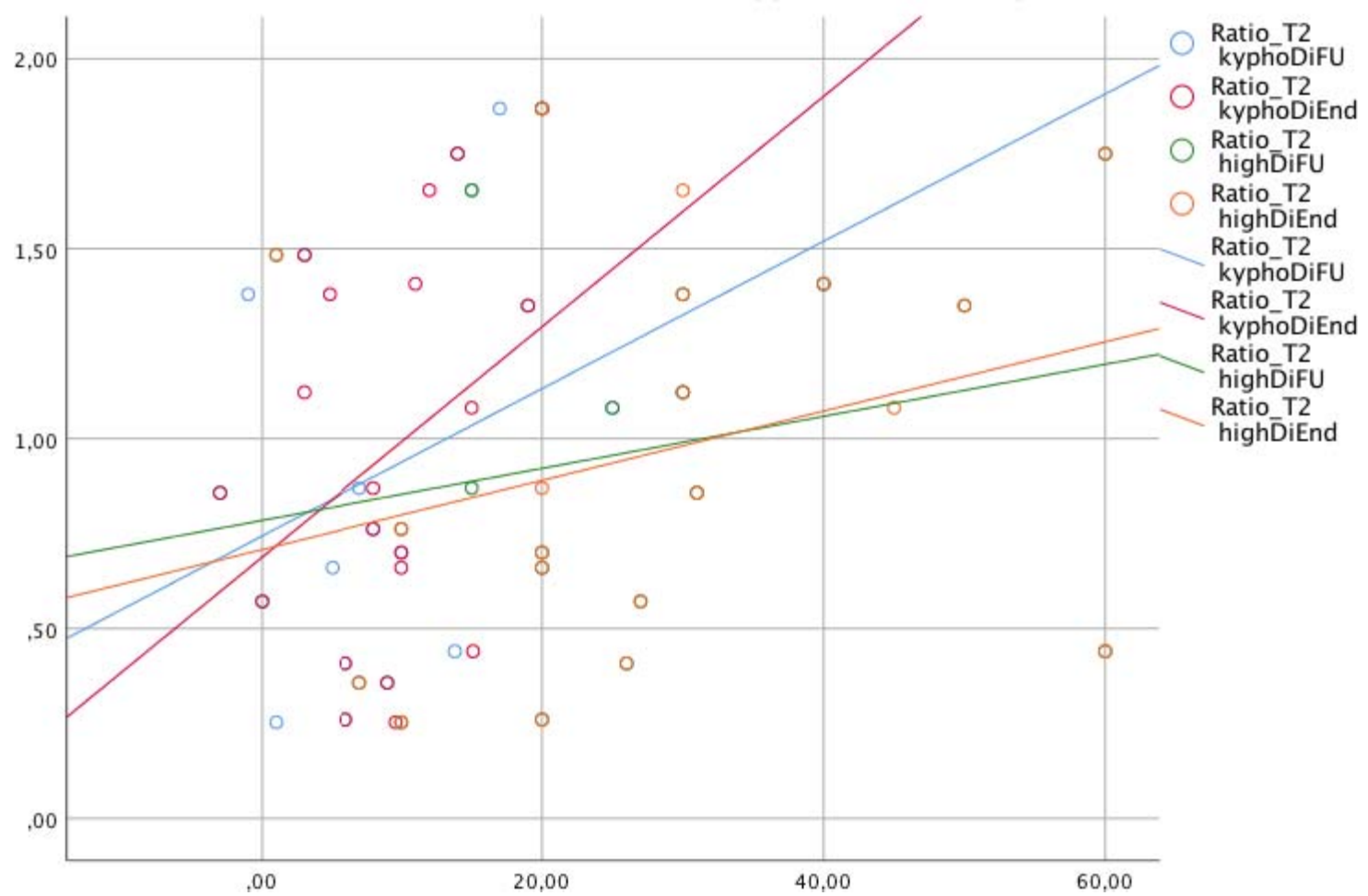

Figure 2. Correlation of SR (T2) to kyphosis progression until follow-up end and height reduction until follow-up end.

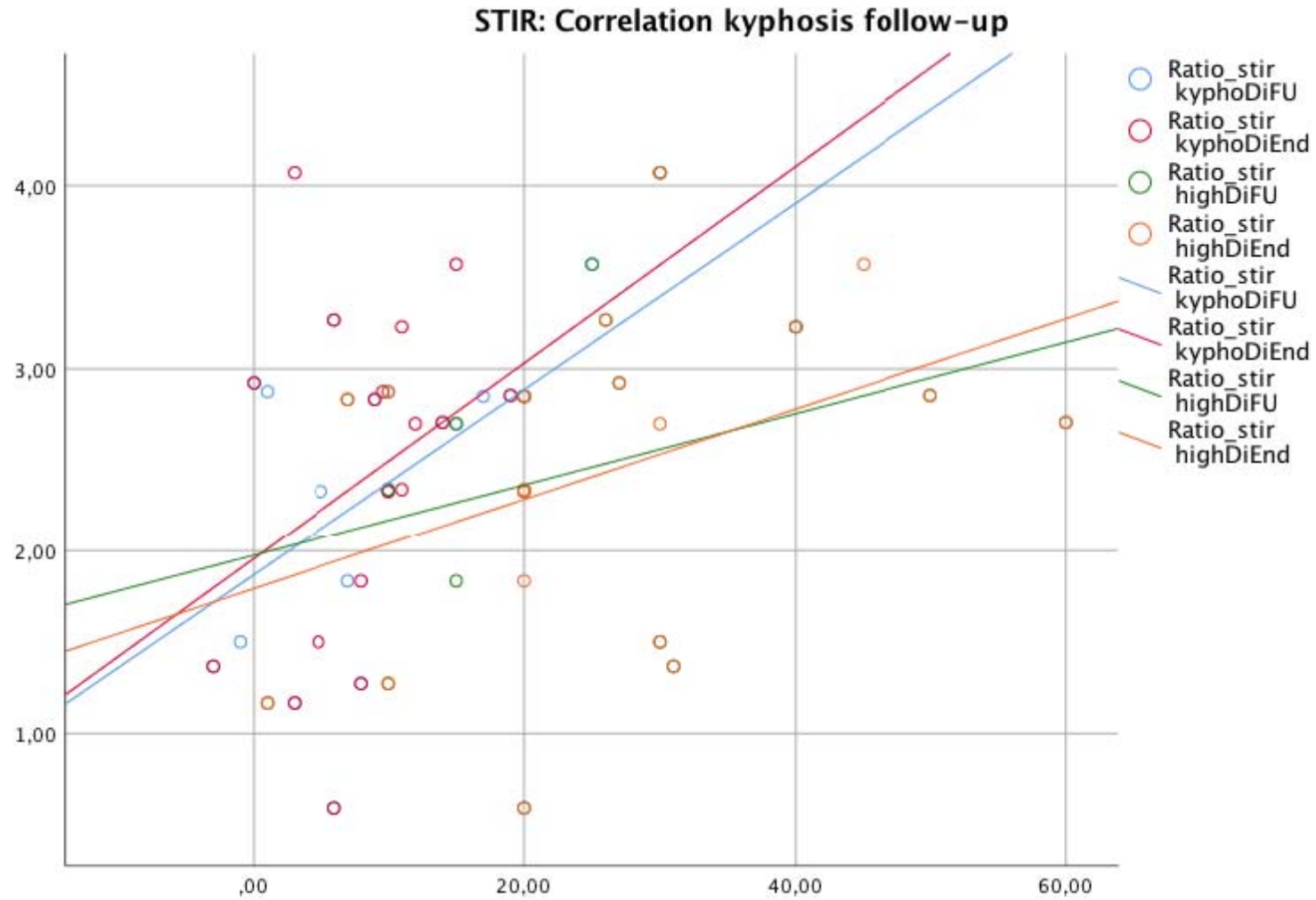

Figure 3. Correlation of SR (STIR) to kyphosis progression till follow-up end and of height reduction till follow-up end. 
Table 2. Findings of regression analysis: $P$ values and $R^{2}$ of progress in kyphosis and height reduction.

\begin{tabular}{|c|c|c|c|c|c|c|c|c|}
\hline & \multicolumn{2}{|c|}{$\begin{array}{l}\text { Kyphosis } \\
\text { Follow-up }\end{array}$} & \multicolumn{2}{|c|}{$\begin{array}{l}\text { Kyphosis } \\
\text { End }\end{array}$} & \multicolumn{2}{|c|}{$\begin{array}{c}\text { Height } \\
\text { Follow-up }\end{array}$} & \multicolumn{2}{|c|}{$\begin{array}{l}\text { Height } \\
\text { End }\end{array}$} \\
\hline & $P$ & $R^{2}$ & $P$ & $R^{2}$ & $P$ & $R^{2}$ & $P$ & $R^{2}$ \\
\hline STIR & .002 & .565 & .017 & .156 & .688 & .113 & .457 & .030 \\
\hline T2 & .001 & .565 & .146 & .156 & .125 & .113 & .325 & .030 \\
\hline
\end{tabular}

correlated from the time of the final examination $(P$ $=.146 ; \mathrm{SD} \pm 2.016)$.

The height reduction results for both STIR and T2 measurements are not significant: $P=.688$ (SD \pm 4.310) for STIR, respectively 0.125 (SD \pm 6.210) for T2 in follow-up; $P=.457(\mathrm{SD} \pm 3.206)$ in STIR, respectively 0.325 ( $\mathrm{SD} \pm 4.664)$ in $\mathrm{T} 2$ in the final examination (Table 2).

Progressive kyphosis also remains significant under the STIR weighting until final examination $(P=.017 ; \mathrm{SD} \pm 1.360)$. On average to the end of the follow-up, group 3 shows an increase of kyphosis by $7.75^{\circ}$ (SD \pm 2.15 ; Figure 4 ) and the associated group 4 even an average of kyphosis by $10.63^{\circ}$ (SD \pm 1.58; Figure 5).

\section{DISCUSSION}

Fractures of the spine are a major player in trauma surgery specially in osteoporotic patients and will continue to increase in the future due to demographic change. ${ }^{4}$

In this study, we correlate the kyphotic tendency of an osteoporotic vertebral body fracture based on the MRI signal and the SSIR, which might be helpful for decision-making in the future. We found that if a quotient of the signal intensity is calculated using the edema-induced signal increase and the CSF signal, the affected vertebral body has a tendency to develop kyphosis in the further course. However, a significant correlation of ratio, progression, and persistent instability is only given in the STIR sequences. For the STIR weighting, it can be shown that distributing the ratios to the quotient groups as described in the Method section reveals a clear indication that from a ratio $>=2$ (groups 3 and 4), a pronounced kyphosis may be expected in the course (Figures 4 and 5). In the T2 weights, the results for the final survey are not significant.

The average progressive kyphosis increases significantly using STIR weighting until final examination on average to the end of follow-up, as group 3 shows an increase of kyphosis by $7.75^{\circ}$ and the associated group 4 even an average of kyphosis by $10.63^{\circ}$.

Increasing kyphosis may generate a biomechanical situation, which may increase the occurrence of further osteoporotic fractures, as an increasing kyphotic deformity can shift the patient's center of gravity. This results in greater flexion bending moments around the apex of the kyphosis, which will promote further increases in kyphotic angulation and additional fractures. ${ }^{23,24}$

Further data from larger studies are required; however, a SSIR-STIR greater than 2 is consistent with further kyphotic angulation in the course, so

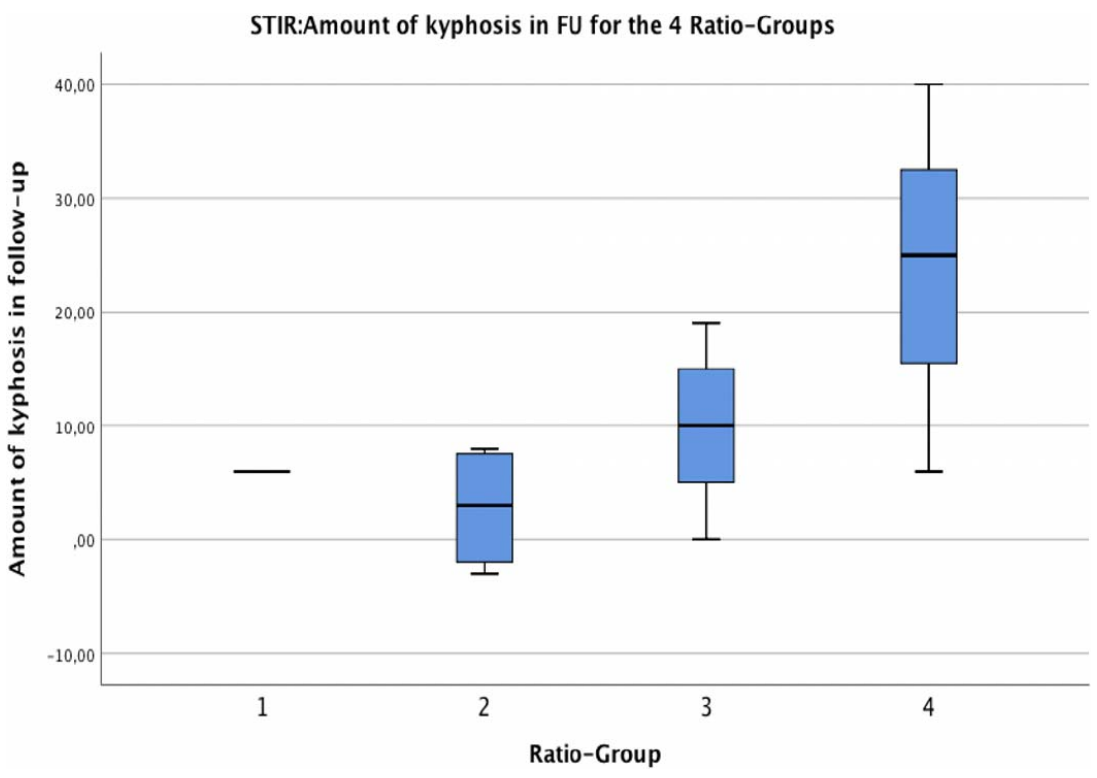

Figure 4. Boxplot SR-STIR for kyphosis follow-up divided in the 4 groups. 


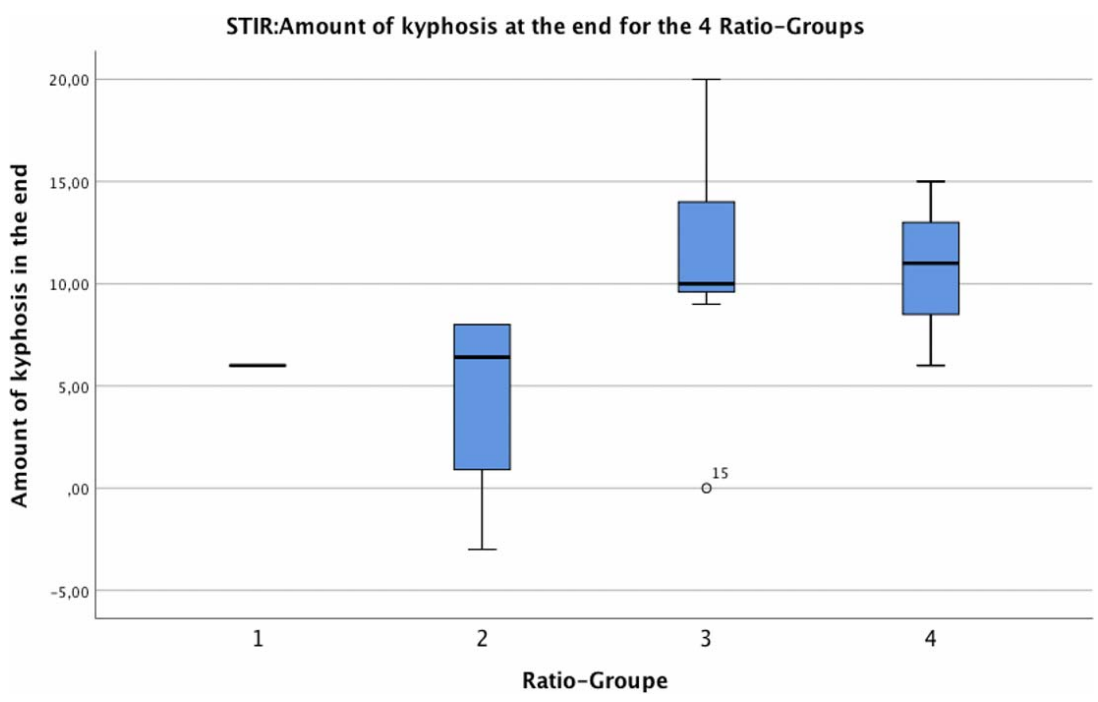

Figure 5. Boxplot SR-STIR for kyphosis till end divided in the 4 groups.

that the authors consider that either kyphoplasty or vertebroplasty or shorter intervals for $\mathrm{x}$-ray have to be considered.

In this study, the STIR-weighted measurements showed the strongest correlation with a strong significance at follow-up $(P=.002 ; \mathrm{SD} \pm 2.664)$ and for the final examination $(P=.017$; SD \pm 1.360 ), even if the STIR weighting is generally an unspecific parameter for edema.

This study has several limitations. Examining the correlation of $\mathrm{T}$-scores, medication, and other clinical data like the pain level was not possible due to inconsistent data.

The main limitations are, however, confounders that change a STIR signal but have no direct connection to osteoporotic fractures.

The influence of hyperemia, infection, and the degree of osteoporosis was not part of this study but should be considered in further studies.

Furthermore, it must be clearly differentiated that with progression an initially strong kyphosis can decrease in the further course due to progressive collapse of the trailing edge, along with a collapse of the vertebral body over its entire width. Even if the direct measurement of kyphosis angle would show lower decrease, this still means a progress and thus an instability. Accordingly, it is conceivable that, due to the design of the study, very unstable fractures due to their total collapse and the associated reduction in the kyphosis-angle were falsely not included in our evaluation. Furthermore, compliance with the follow-up appointments was low, so that significantly fewer patients than initially screened could finally be included in the evaluation.
In addition, the inconsistent follow-up time and final examination due to retrospective design may have an impact on the collected data, as for example patients with a follow-up examination of 1 month and that of 12 months were compared.

\section{CONCLUSIONS}

In this study, we present the idea to assess the likelihood of further kyphosis of osteoporotic fractures due to different SSIRs. The data from this study might show a significant correlation of progressive kyphosis with increasing SSIR. Surgical intervention might be considered in patients in groups 3 and 4 , because a further kyphosis is seen in these patients in our study. Nevertheless, due to the strong limitations following from short follow-up, further studies including higher patient numbers and prospective randomized trials are recommended for further clarification of this finding.

\section{REFERENCES}

1. Mäyränpää MK, Viljakainen HT, Toiviainen-Salo S, Kallio PE, Mäkitie O. Impaired bone health and asymptomatic vertebral compressions in fracture-prone children: a casecontrol study. J Bone Miner Res. 2012;27(6):1413-1424. doi:10.1002/jbmr.1579

2. Kendler DL, Bauer DC, Davison KS, et al. Vertebral fractures: clinical importance and management. Am J Med. 2016;129(2):221.e1-221.e10. doi:10.1016/j.amjmed.2015.09.020

3. Saul D, Dresing K. Epidemiology of vertebral fractures in pediatric and adolescent patients. Pediatr Rep. 2018;10(1). doi:10.4081/pr.2018.7232

4. Ballane G, Cauley JA, Luckey MM, El-Hajj, Fuleihan G. Worldwide prevalence and incidence of osteoporotic vertebral 
fractures. Osteoporos Int. 2017;28(5):1531-1542. doi:10.1007/ s00198-017-3909-3

5. Scheyerer MJ, Ullrich B, Osterhoff G, Spiegl UA, Schnake KJ; Arbeitsgruppe Osteoporotische Frakturen der Sektion Wirbelsäule der Deutschen Gesellschaft für Orthopädie und Unfallchirurgie. [Hounsfield units as a measure of bone density-applications in spine surgery]. Article in German. Unfallchirurg. 2019;122(8):654-661. doi:10.1007/s00113-0190658-0

6. Joestl J, Lang N, Bukaty A, Tiefenboeck TM, Platzer P. Osteoporosis associated vertebral fractures - Health economic implications. PLoS One. 2017;12(5):e0178209. doi:10.1371/ journal.pone.0178209

7. McCarthy J, Davis A. Diagnosis and management of vertebral compression fractures. Am Fam Physician. 2016;94(1):44-50.

8. Gonschorek O, Hauck S, Weiß T, Bühren V. Percutaneous vertebral augmentation in fragility fractures - indications and limitations. Eur J Trauma Emerg Surg. 2017;43(1):9-17. doi:10.1007/s00068-016-0753-7

9. Ender SA, Eschler A, Ender M, Merk HR, Kayser R. Fracture care using percutaneously applied titanium mesh cages (OsseoFix ${ }^{\circledR}$ ) for unstable osteoporotic thoracolumbar burst fractures is able to reduce cement-associated complicationsresults after 12 months. J Orthop Surg Res. 2015;10(1):175. doi:10.1186/s13018-015-0322-5

10. Wiedl A, Förch S, Fenwick A, Mayr E. [Importance of surgical treatment of thoracolumbar vertebral fractures for the survival probability of orthogeriatric patients]. Article in German. Unfallchirurg. 2021;124(4):303-310. doi:10.1007/ s00113-020-00864-w

11. Schnake KJ, Blattert TR, Zimmermann V, et al. Entwicklung einer Klassifikation für osteoporotische Wirbelfrakturen und eines Scores zur therapeutischen Indikationsfindung (OF-Klassifikation und OF-Score). Deutscher Kongress für Orthopädie und Unfallchirurgie (DKOU 2013). Published online 2013. doi:10.3205/13DKOU021

12. Yang E-Z, Xu J-G, Huang G-Z, et al. Percutaneous vertebroplasty versus conservative treatment in aged patients with acute osteoporotic vertebral compression fractures: a prospective randomized controlled clinical study. Spine. 2016;41(8):653-660. doi:10.1097/BRS.0000000000001298

13. Pradhan BB, Bae HW, Kropf MA, Patel VV, Delamarter RB. Kyphoplasty reduction of osteoporotic vertebral compression fractures: correction of local kyphosis versus overall sagittal alignment. Spine. 2006;31(4):435-441. doi:10.1097/01. brs.0000200036.08679.1e

14. Schnake KJ, Scheyerer MJ, Spiegl UJA, et al; Arbeitsgruppe Osteoporotische Frakturen der Sektion Wirbelsäule. [Minimally invasive stabilization of thoracolumbar osteoporotic fractures]. Article in German. Unfallchirurg. 2020;123(10):764-773. doi:10.1007/s00113-020-00835-1

15. Pham T, Azulay-Parrado J, Champsaur P, Chagnaud C, Legré V, Lafforgue P. "Occult" osteoporotic vertebral fractures: vertebral body fractures without radiologic collapse. Spine. 2005;30(21):2430-2435. doi:10.1097/01.brs.0000184303. 86932.77

16. Bierry G, Venkatasamy A, Kremer S, Dosch J-C, Dietemann J-L. Dual-energy CT in vertebral compression fractures: performance of visual and quantitative analysis for bone marrow edema demonstration with comparison to MRI. Skeletal Radiol. 2014;43(4):485-492. doi:10.1007/s00256-0131812-3

17. Cicala D, Briganti F, Casale L, et al. Atraumatic vertebral compression fractures: differential diagnosis between benign osteoporotic and malignant fractures by MRI. Musculoskelet Surg. 2013;97(S2):169-179. doi:10.1007/s12306-0130277-9

18. Spiegl UJA, Beisse R, Hauck S, Grillhösl A, Bühren V. Value of MRI imaging prior to a kyphoplasty for osteoporotic insufficiency fractures. Eur Spine J. 2009;18(9):1287-1292. doi:10.1007/s00586-009-1045-2

19. Francis RM, Aspray TJ, Hide G, Sutcliffe AM, Wilkinson P. Back pain in osteoporotic vertebral fractures. Osteoporos Int. 2008;19(7):895-903. doi:10.1007/s00198-0070530-x

20. Luoma EK, Raininko R, Nummi PJ, Luukkonen R, Manninen HI, Riihimäki HA. Suitability of cerebrospinal fluid as a signal-intensity reference on MRI: evaluation of signalintensity variations in the lumbosacral dural sac. Neuroradiology. 1997;39(10):728-732. doi:10.1007/s002340050496

21. Luoma K, Raininko R, Nummi P, Luukkonen R. Is the signal intensity of cerebrospinal fluid constant? Intensity measurements with high and low field magnetic resonance imagers. Magn Reson Imaging. 1993;11(4):549-555. doi:10. 1016/0730-725X(93)90474-R

22. Smith SA, Xavier G, Ali F, et al. Magnetization transfer weighted imaging in the upper cervical spinal cord using cerebrospinal fluid as intersubject normalization reference (MTCSF imaging). Magn Reson Med. 2005;54(1):201-206. doi: $10.1002 / \mathrm{mrm} .20553$

23. Phillips FM. Minimally invasive treatments of osteoporotic vertebral compression fractures. Spine. 2003;28(suppl):S45S53. doi:10.1097/01.BRS.0000076898.37566.32

24. Belmont PJ, Polly DW, Cunningham BW, Klemme WR. The effects of hook pattern and kyphotic angulation on mechanical strength and apical rod strain in a long-segment posterior construct using a synthetic model. Spine. 2001;26(6):627-635. doi:10.1097/00007632-200103150-00013

Disclosures and COI: The authors received no funding for this study and report no conflicts of interest. Drs Pacha and Ghasemi contributed equally to this article.

Corresponding Author: Tarek Omar Pacha, MD, Trauma Center, Hannover Medical School, Carl-Neuberg-Strasse 1, 30625 Hannover, Germany. Phone:+495115322050; Fax:+495115325837; Email: omarpacha.tarek@mh-hannover.de.

Published 1 June 2021

This manuscript is generously published free of charge by ISASS, the International Society for the Advancement of Spine Surgery. Copyright (C) 2021 ISASS. To see more or order reprints or permissions, see http://ijssurgery.com. 